
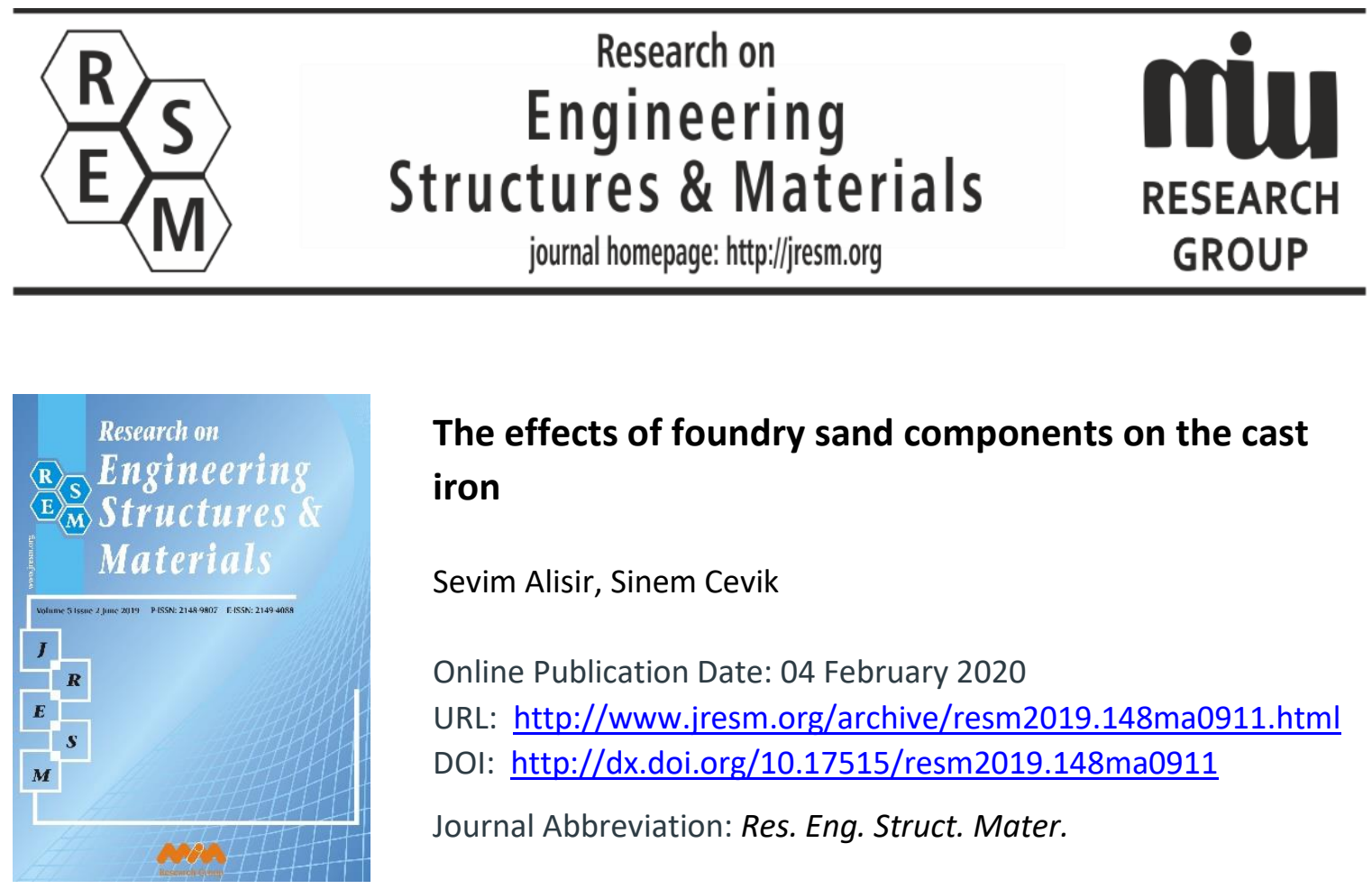

\title{
The effects of foundry sand components on the cast iron
}

Sevim Alisir, Sinem Cevik

Online Publication Date: 04 February 2020

URL: http://www.jresm.org/archive/resm2019.148ma0911.html

DOI: http://dx.doi.org/10.17515/resm2019.148ma0911

Journal Abbreviation: Res. Eng. Struct. Mater.

\section{To cite this article}

Alisir S, Cevik S. The effects of foundry sand components on the cast iron. Res. Eng. Struct. Mater., 2020; 6(2): 127-140.

\section{Disclaimer}

All the opinions and statements expressed in the papers are on the responsibility of author(s) and are not to be regarded as those of the journal of Research on Engineering Structures and Materials (RESM) organization or related parties. The publishers make no warranty, explicit or implied, or make any representation with respect to the contents of any article will be complete or accurate or up to date. The accuracy of any instructions, equations, or other information should be independently verified. The publisher and related parties shall not be liable for any loss, actions, claims, proceedings, demand or costs or damages whatsoever or howsoever caused arising directly or indirectly in connection with use of the information given in the journal or related means.

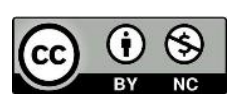

Published articles are freely available to users under the terms of Creative Commons Attribution - NonCommercial 4.0 International Public License, as currently displayed at here (the "CC BY - NC"). 


\title{
Research on Engineering Structures \& Materials
}

journal homepage: http://jresm.org

Research Article

\section{The effects of foundry sand components on the cast iron}

\author{
Sevim Alisira, ${ }^{\text {, }}$, Sinem Cevik ${ }^{\mathrm{b}}$ \\ Department of Metallurgy and Materials Engineering, Ondokuz Mayis University, Samsun, Turkey
}

\begin{tabular}{|c|c|}
\hline rt & bstract \\
\hline $\begin{array}{l}\text { Article history: } \\
\text { Received 11 Sep } 2019 \\
\text { Revised 15 Jan } 2020 \\
\text { Accepted } 17 \text { Jan } 2020 \\
\end{array}$ & \multirow{7}{*}{$\begin{array}{l}\text { Many studies are being carried out on factors such as casting temperature, } \\
\text { cooling rate, mold design and, so on due to the effects of casting and } \\
\text { solidification conditions on the mechanical properties of the final product. } \\
\text { However, given literature, there appears to be no comprehensive study on the } \\
\text { effect of casting mold sand components on the mechanical properties of cast } \\
\text { iron. From this point of view within the scope of this study, the effects of casting } \\
\text { mold sand and binder on the cast iron were investigated. By using silica and } \\
\text { olivine as foundry sand at different ratios, bentonite and perlite as binders, the } \\
\text { effects of them on the microstructure and the mechanical properties of casting } \\
\text { were investigated. The microstructures of the products show that as the cooling } \\
\text { rate slows down, the distribution of graphite particles in the structure changes } \\
\text { from flakes to nodules. These structural changes are very matched with the } \\
\text { results of mechanical properties. Therefore, when the cooling rate decreases, } \\
\text { the hardness decreases from } 310 \text { HV to } 239 \text { HV in all of the groups. Also, the } \\
\text { bending strength is going from } 971.53 \text { MPa to } 487.42 \text { MPa, like in the hardness } \\
\text { results. On the contrary, the deformation increases from } 13 \% \text { to } 24 \% \text { when } \\
\text { cooling rates decreases. This study clearly demonstrates that the products can } \\
\text { be obtained by changing the heat conduction coefficient of the casting mold } \\
\text { with different mechanical properties from the same molten metal. }\end{array}$} \\
\hline Keywords: & \\
\hline Four & \\
\hline Cast iron; & \\
\hline Microstructure; & \\
\hline & \\
\hline Perl & \\
\hline
\end{tabular}

(c) 2019 MIM Research Group. All rights reserved.

\section{Introduction}

The alloy of iron in which the carbon ratio is $2-4 \%$, is usually called cast irons. They are hard and brittle. Because of the brittle character, they can be produced by the method of casting [1]. They include much more silicon ( $\max 3.5 \%$ ) and phosphorus (max $2 \%$ ) content than steels do. The microstructure (containing phases and the distribution of these phases) and mechanical properties of cast iron depend on chemical composition (especially carbon and silicon content) and cooling rate. Cast irons have many advantages in terms of both castings and finished parts. They have $20-40 \%$ lower production cost than steels, good fluidity (increases when approaches eutectic composition), good vibration damping, high compression strength, low volume shrinkage during solidification, high corrosion and wear resistance. Cast irons are used especially in the automotive industry as crankshaft, piston ring and, the parts of brake system.

The gray cast iron of which the fracture surface seems gray is one of the kinds of cast iron. It is a widely used cast material. The carbon in its composition is in the form of free graphite flakes or iron carbide (cementite) after solidification. The size, distribution, and shape of the incorporated graphite particles in gray cast iron significantly affect the mechanical properties of product. They can be controlled by adding a large number of

\footnotetext{
${ }^{*}$ Corresponding author: sevimh@omu.edu.tr

a orcid.org/0000-0001-7296-8318; b orcid.org/0000-0002-3506-7892

DOI: http://dx.doi.org/10.17515/resm2019.148ma0911

Res. Eng. Struct. Mat. Vol. 6 Iss. 2 (2020) 127-140
} 
alloying elements ( $\mathrm{Ni}, \mathrm{Cr}, \mathrm{Mo}, \mathrm{Al}, \mathrm{Cu}, \mathrm{Mg}, \mathrm{S}$, etc.), [2-5] or by changing the cooling rate of the molten metal [6].

Many casting methods and different molding materials are also used in the iron casting industry, depending on the size and mechanical properties of the desired product. Among the techniques used, the sand molding method is irreplaceable due to its suitability to different product sizes and compositions, the reuse of the molding sand, and its low cost [7].

In the sand-casting method, first molten metal is poured to sand mold, then waited for a while to permit the metal to solidify in the mold. There are two major factors that determine to great extent the soundness of the final casting produced in this method. The first factor, graphitization, is the process in which free carbon is precipitated in iron, or the chemically bonded carbon $\left(\mathrm{Fe}_{3} \mathrm{C}\right)$ is replaced by free carbon (or graphite). The second factor that significantly influences the microstructure of cast iron is the cooling rate during solidification. It is also a very useful parameter in the graphitization process.

The cooling rate defines the solidification time of molten metal and varies depending on the heat conduction coefficient of the mold. At an industrial level, the quality of the molding sands is crucial to provide high- grade castings. Because the heat conduction coefficient of the mold changes as the mold components change. The cooling rate can be controlled by using molding components of different types or compositions to obtain the product with the desired mechanical properties. So, the most important point in this technique is the adjustment of sand components.

When the studies done to date are examined, it is seen that many factors mentioned above affect the microstructure and mechanical properties of cast iron.

In the study of Gupta et al., the distribution of graphite clusters in the product was investigated by using three different mold systems, which include green sand mold, dry sand mold, and $\mathrm{CO}_{2}$ sand mold. The methods used in production are effective on microstructure and mechanical properties (such as tensile strength, Brinell hardness, and Charpy impact test) [8].

Górny and Tyrala investigated the effect of cooling rate on microstructure and mechanical properties as determined by changing molding media and section size. Thinwalled iron castings with 2-5-mm wall thickness and different molding materials (silica sand and insulating sand "LDASC") were used to obtain various cooling rates. In the study, the gray cast iron used was hyper-eutectic, with a $\mathrm{C}_{\text {eq }}$ value of 4.58 [9].

In his studies, Sjogren changed the shape of the graphite in the microstructure by adjusting the amount of magnesium in eutectic cast iron. In the report, experiments confirmed the importance of micro-yielding of the matrix at the tip of the graphite particles on the macro-elastic behavior of the studied cast irons. It was determined that the macro-stress and macro-strain values of the flake graphite cast iron are very lower than in the case of the compacted graphite cast iron [4].

The researches given above showed that the main factor underlying the change in properties of the product is the change of cooling rate. As is known, the heat conduction coefficient of the mold also depends on the casting mold components. To our knowledge, there is only one systematic study in the literature that shows the effect of mold components on the microstructure and mechanical properties of the product obtained from cast iron.

An experiment was done by Adedayo to investigate the effects of additions of iron fillings to green molding sand on the microstructure of gray cast iron. For this experiment, five sand samples were prepared with different Fe content ranging from $1 \mathrm{wt} \%$ to $5 \mathrm{wt} \%$. The 
properties of the sand samples were tested and used to cast some grey cast iron samples whose microstructure was observed by optical microscopy. The results show that the addition of Fe filing does not have any adverse effects on the properties of green molding sand; however, the microstructures show a dependence on the heat storage capacity of the mold [10].

In the present study, it was examined how mold sand and binder used in the production of cast iron affect the microstructure and mechanical properties of the final product. For this purpose, two different foundry sands (olivine and silica sand) and two different binders (bentonite and perlite) were used in our study.

\section{Materials and Methods}

\subsection{Casting Process}

The different kinds of metallic scraps were used to prepare molten metal (in Fig. 1a). Melting was performed in an intermediate frequency electric induction furnace in a 100 $\mathrm{kg}$ crucible (in Fig. 1b). After the scrap metal was heated to $1490^{\circ} \mathrm{C}$, the molten cast iron was poured into the sand mold at $1450{ }^{\circ} \mathrm{C}$ (in Fig. 1c). Three samples were poured for every sub working groups.

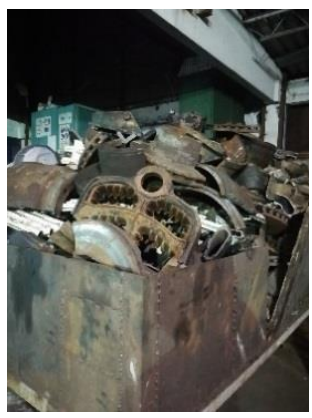

(a)

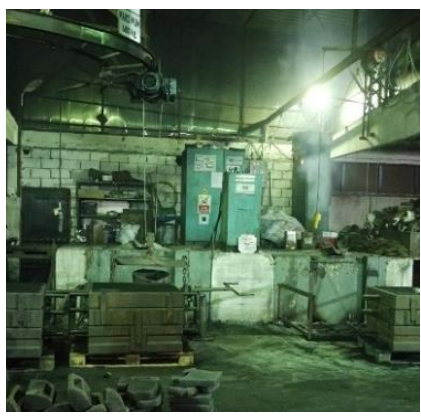

(b)

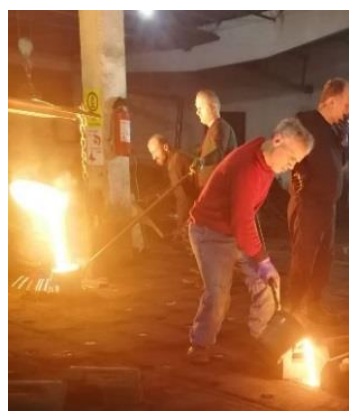

(c)

Fig. 1 Casting process

The chemical composition analysis of the investigated gray cast iron was made with Foundry Master Spectrometer by measuring from five different regions to determine the homogeneity of the castings and reported in Table 1.

Table 1. The chemical compositions of the investigated cast iron

\begin{tabular}{cccccc}
\hline $\mathrm{Fe} \%$ & $\mathrm{C} \%$ & $\mathrm{Si} \%$ & $\mathrm{Mn} \%$ & $\mathrm{P} \%$ & $\mathrm{Si} \%$ \\
\hline 92.950 & 2.717 & 3.085 & 0.595 & 0.154 & 0.025 \\
\hline
\end{tabular}

\subsection{Mold preparation process}

In this study, two different sands were used as mold sands. The first is silica; the other is olivine. Also, all molding sand components were prepared to contain approximately $8.8 \%$ binder. Two different binders (bentonite and perlite) were added to each group. 
Bentonite, which is a kind of clay, can be used as a binder material in sand molding process. It includes montmorillonite and volcanic ash predominantly, and it is in the mineral group of aluminosilicates. It provides mold sands good flowability, compatibility, and thermal stability for the production of high-quality castings [11]. In this study, CANDOK foundry grade bentonite is used as a binder (in Fig. 2a).

Perlite is importantly useful material for heat insulation. It is also known as a lightweight material [12]. Turkey has $70 \%$ of world reserves. Therefore, expanded perlite was selected as the other binder and provided by AKPER (in Figure $2 b$ ).

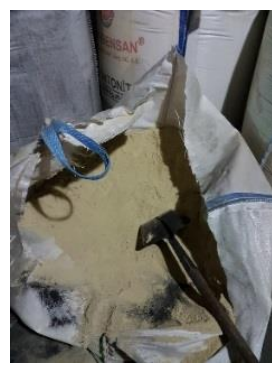

(a)

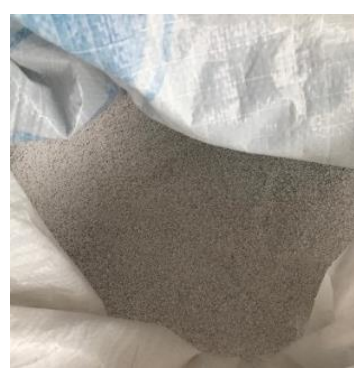

(b)

Fig. 2 Used binders (a) bentonite and (b) perlite

In the first working group, the amount of silica sand and coke powder was kept approximately constant. But the amount of bentonite and perlite used as the binder in sand mold were changed (in Table 2). For second working group was used olivine instead of silica sand, and other ingredients remained the same. For each group the effects of the change in the ratio of bentonite and perlite at all composition were investigated individually on the quality of castings.

The composition of the mold sands and the sample code in experimental working groups can be seen in Table 2 and Fig. 3, respectively.

Table 2. Mold compositions ( ${ }^{*} \mathrm{WG}$ : working group)

\begin{tabular}{|c|c|c|c|c|c|c|}
\hline & Samples & Mold sand (\%) & Coke powder (\%) & Bentonite (\%) & Perlite (\%) & $\begin{array}{c}\text { Water } \\
(\%)\end{array}$ \\
\hline \multirow{3}{*}{ 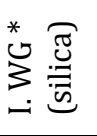 } & 1.1 & 78.89 & 8.87 & 8.87 & None & 3.37 \\
\hline & 1.2 & 78.82 & 8.78 & 3.90 & 4.97 & 3.53 \\
\hline & 1.3 & 78.82 & 8.78 & None & 8.78 & 3.53 \\
\hline \multirow{3}{*}{ 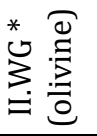 } & 2.1 & 78.89 & 8.87 & 8.87 & None & 3.37 \\
\hline & 2.2 & 78.82 & 8.78 & 3.81 & 5.06 & 3.53 \\
\hline & 2.3 & 78.82 & 8.78 & None & 8.87 & 3.53 \\
\hline
\end{tabular}



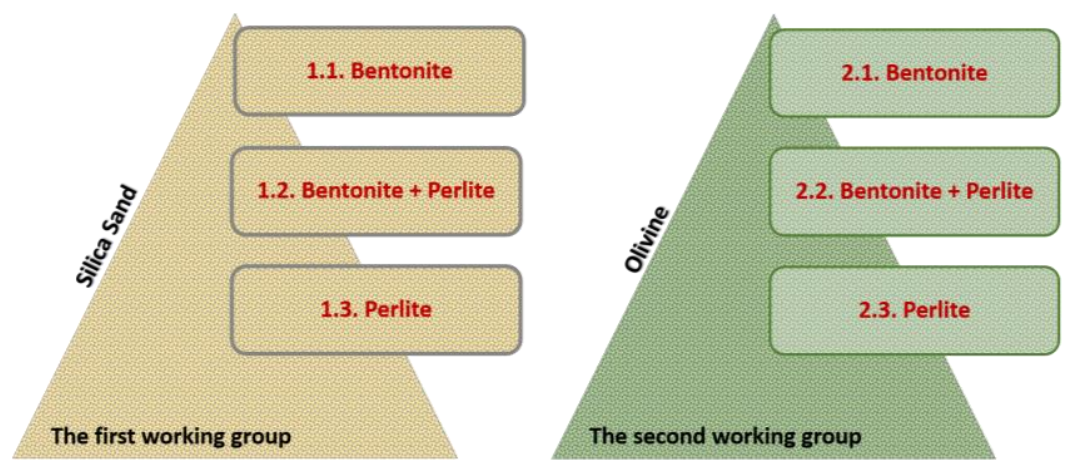

Fig. 3 The sample code in experimental working groups

The samples with dimensional $40 \times 40 \times 40 \mathrm{~mm}$ and $40 \times 40 \times 150 \mathrm{~mm}$ were produced in the foundry. The prearranged model (in Fig. 4a) and feeder were put into mold sand for the casting process (in Fig. 4b). Mold sands that were mixed in specific proportions according to their recipes were supported and pressed. Then the molten metal was poured to mold sands by ladle. The pictures for mold preparation are shown in Fig. 4 . Some parameters, the chemical composition of castings and molding time, were held as constant as possible during the casting process.

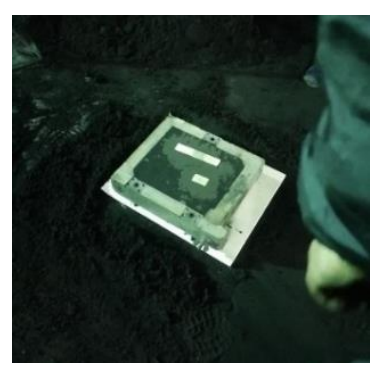

(a)

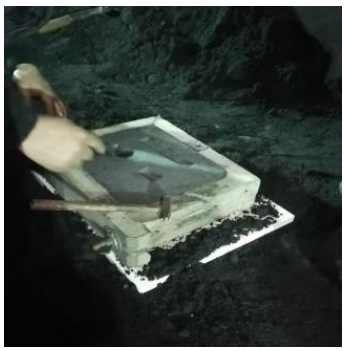

(b)

Fig. 4 Mold preparation process

\subsection{Characterizations of the sample}

After the casting process, the sample was mounting with bakelite for the optical microscope. Then the surface of the samples was ground and polished to observe the microstructure of samples (in Fig 5). The etching was made by using of $5 \%$ nital solution.

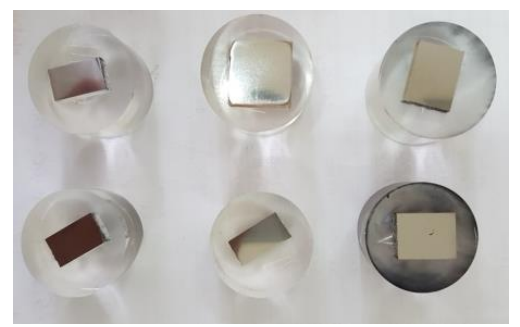

Fig. 5 Preparation of the samples for optical microscope. 
To evaluate the microstructure of the castings and to observe surface defects, Leica DM2500P model light microscope connected to computer equipped with image analysis software was used.

The tensile tests were conducted 10 tone universal MARES tension-compression test unit (in accordance with ASTM E9 standard). The cube-shaped samples with dimensions 25 $\mathrm{mm} \times 25 \mathrm{~mm} \times 25 \mathrm{~mm}$ was used for compression tests.

The hardness test was performed using TMTECK HV-1000B model hardness tester at the load of 200 gf. In order to obtain an average hardness value, measurements were taken from at least 10 different regions.

Three-point bending tests were performed (in accordance with ASTM E855) by GUNT, Wp300 model device. During test, bearer length was adjusted as $100 \mathrm{~mm}$, and test maintained until samples were broken (in Fig. 6).

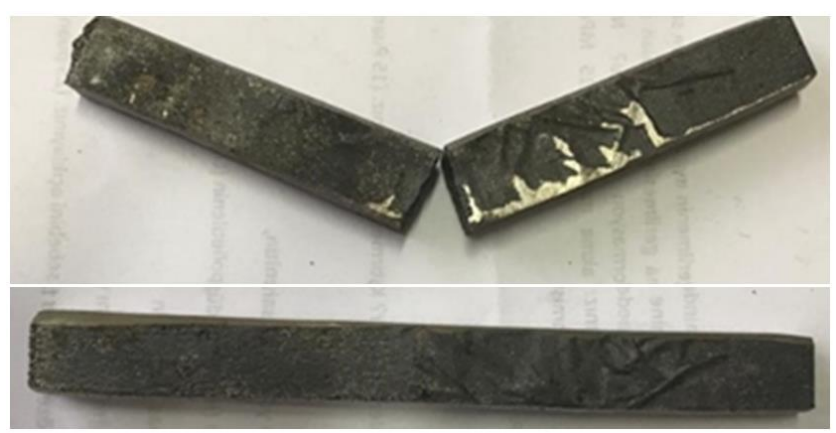

Fig. 6 Three-point bending test samples

\section{Results and Discussion}

The effects of used mold sand and binder on the microstructure and mechanical properties of cast iron are the main objectives of the present study. Therefore, working groups were formed in order to observe the mold sand and binding effect on the product more clearly (as seen in Fig. 3).

\subsection{Analysis of Chemical Compositions}

After spectral chemical analysis, to define the type of final castings, the results were compared to cast iron compositions, and carbon equivalent was calculated by helping Equation 1 [11].

$\mathrm{C}_{\text {eq }}=\% \mathrm{C}+(\% \mathrm{Si}+\% \mathrm{P}) / 3$

The carbon equivalent value $\left(\mathrm{C}_{\mathrm{eq}}=3.79\right)$ was found, and from these findings, it is clear that the final cast product is solidified as a gray cast iron. It is evaluated as hypoeutectic gray cast iron since $\mathrm{C}_{\mathrm{eq}}$ value is lower than $4.25 \%$ [13]. 


\subsection{Mechanical Properties}

The stress-strain diagrams for the samples according to their codes have been shown in Fig. 7. It is seen that in both of the sample groups, provided cast iron molded by bentonite addition has got a positive effect on the strength of the cast iron. Perlite addition to mold sand decreases the max strength of castings. It is concluded that cast samples prepared by the molds with only perlite addition have the lowest max strength. However, the castings produced in silica sand mold has more max strength than the others molded by using olivine sand shown in Fig. 8. In Table 3, it is seen the thermal conductivities of some of the different kinds of sands and clays. Among these silica sand has the highest thermal conductivity with $7.7 \mathrm{~W} / \mathrm{m}$. K. Therefore, its thermal conductivity is almost twice olivine's sand. The produced gray cast irons molded with silica sand has got a high cooling rate.

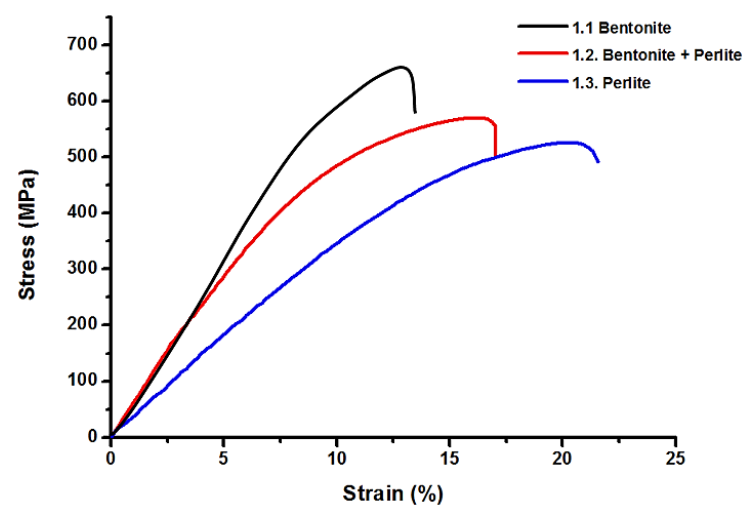

(a)

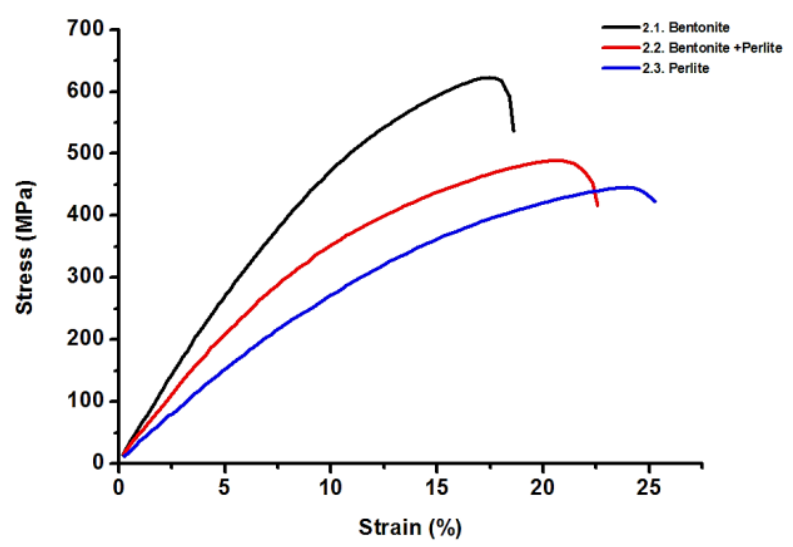

(b)

Fig. 7 Stress-strain diagram of produced sample (a) first, (b) second working group.

As seen in Fig 7a, the increasing cooling rate leads to rising max compression strength. Bentonite has a higher thermal conductivity than perlite (as seen in Table 3). It was determined that compressive strength decreased from bentonite (presented with 1.1 
sample code, $660.70 \mathrm{MPa}$ ) to perlite (presented with 1.3 sample code, $526.03 \mathrm{MPa}$ ) in the same working group. However, ductility was observed to increase.

Table 3 Thermal conductivities of some of the different kinds of clays and sands

\begin{tabular}{ccc}
\hline Various clays and sands & Thermal conductivity $(\mathrm{W} / \mathrm{m} . \mathrm{K})$ & References \\
\hline Silica sand (Quartz) & 7.7 & {$[14]$} \\
Olivine & 4.6 & {$[14]$} \\
Bentonite & 1.15 & {$[15]$} \\
Perlite & 0.0547 & {$[15]$} \\
\hline
\end{tabular}

A similar change was observed in the second working group (in Fig 7b). It was determined that the compressive strength decreased from 622.5 to $445.5 \mathrm{MPa}$ (sample 2.1 and 2.3, respectively).

Moreover, a similar effect was observed in molding sand exchange. The compressive strength of the product obtained from the mold of silica sand with rapid cooling was found to be $660.7 \mathrm{MPa}$, while the compressive strength of the product obtained from the slower cooling olivine was determined to be $622.5 \mathrm{MPa}$ (presented with 1.1 and 2.1 sample codes, respectively). The same binder (bentonite) was used in the preparation of mold of these two samples.

So, the gray cast irons molded by high bentonite addition have higher maximum strengths in the two working groups (in Fig 8). It is concluded that perlite (low thermal conductivity) addition to mold sand has a negative effect on the maximum compression strength of the provided cast irons.

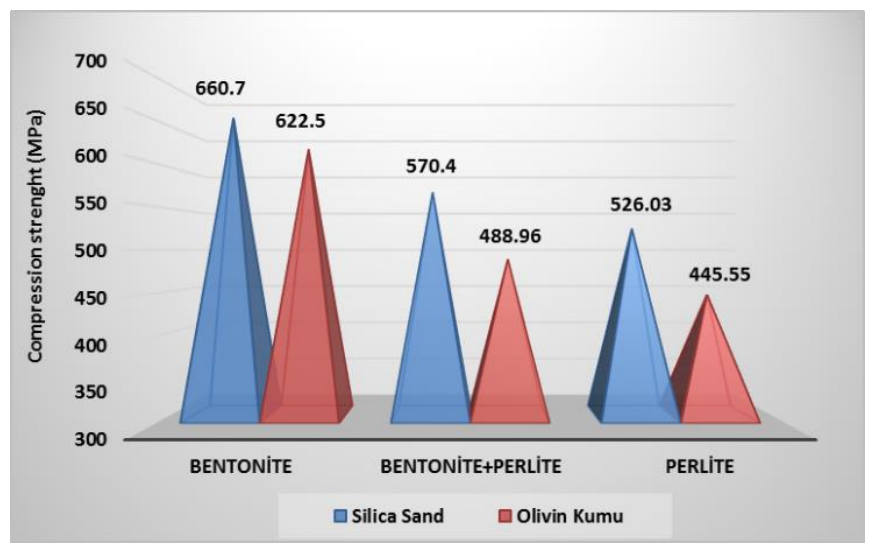

Fig. 8 Maximum strength of castings prepared in molds by silica and olivine sand

Similar results were observed in Ref. 16. In there, Adedayo shows that the heat storage capacity (HSC) of the mold has significant effects on the microstructure and properties of gray iron. He suggests that HSC of mold could be varied as required to effect changes in the microstructure, tensile strength, elongation, hardness, and toughness of gray iron.

It is also observed that after tensile- compression test, the samples are fractured at $45^{\circ}$ (in Fig. 9). 


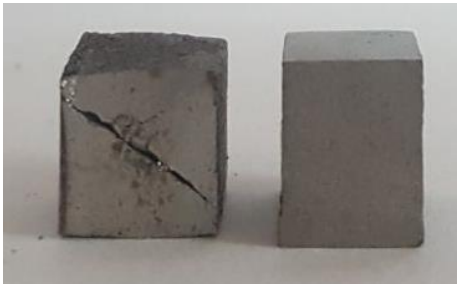

Fig. 9 Fractured samples after tensile- compression test

Hardness is a measure of a material's resistance to localized plastic deformation (e.g., a small dent or a scratch). Hardness tests are usually made to evaluate the materials' mechanical properties. It is also clearly known that when the cooling rate decreases, the hardness decreases, so there is a direct relationship between the hardness, cooling rate, and max strength [17]. In Fig. 10 demonstrates the hardness test results of sample groups. In the first study groups (silica sand) due to the fact that the binder, bentonite, with a higher thermal conductivity coefficient has a faster cooling, the harder material was obtained. In the second study group (olivine sand), similar results are observed.

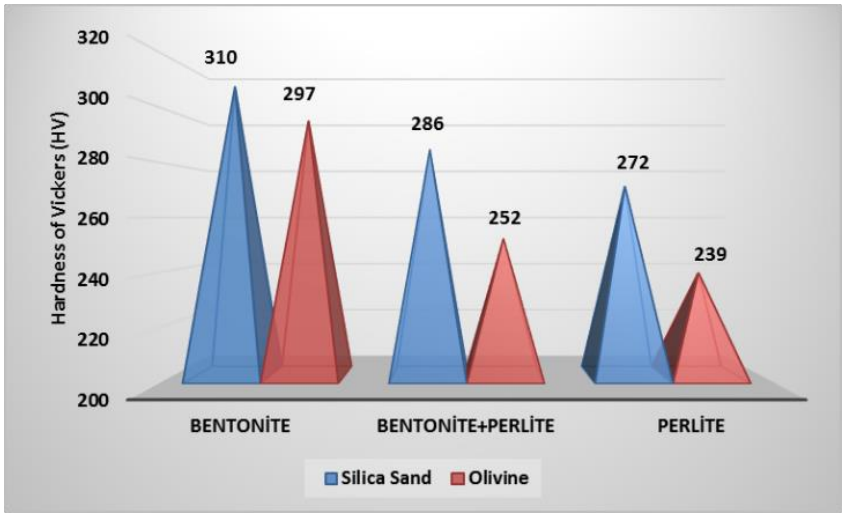

Fig. 10 Hardness values of castings prepared in molds by silica and olivine sand

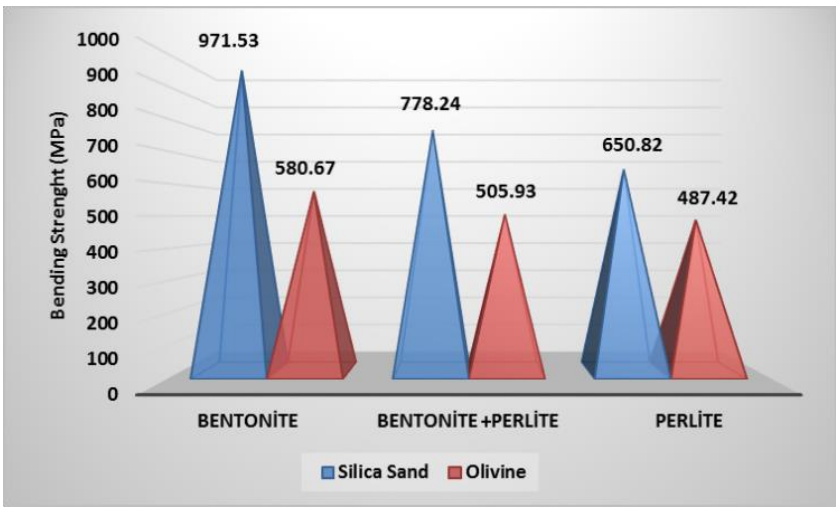

Fig. 11 Three- point bending test results of castings prepared in molds by silica and olivine 
The results of three- point bending test show that increasing hardness (increasing cooling rate) leads to increasing bending strength (Fig. 11). The provided three- point bending test results for both of the study groups are very consistent with the compression and hardness test results (Fig. 12).

As a result, for working group 1, as seen in Fig. 12 the cooling rate decreased, bending stress and hardness decreased while ductility increased. Also, for the second group, the cooling rate decreased, bending stress and hardness decreased while ductility increased (in Fig. 13).

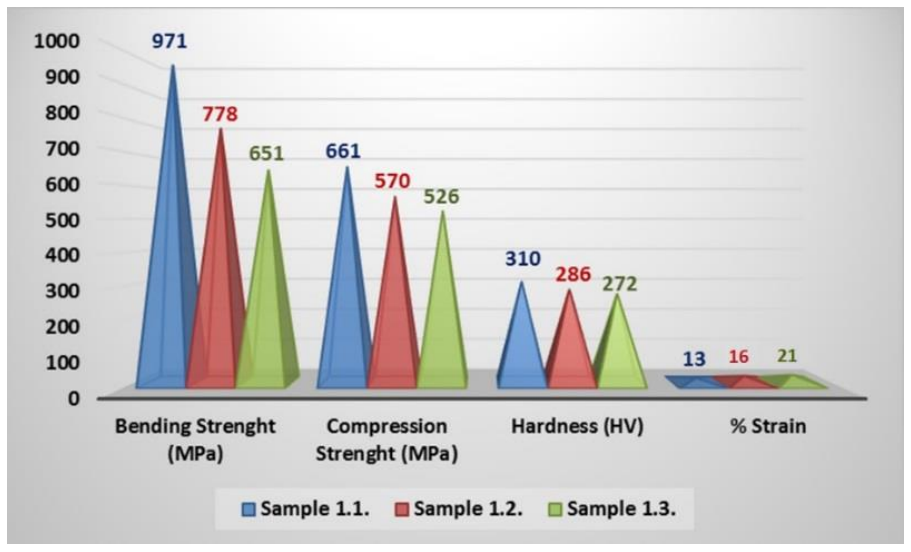

Fig. 12 The comparative mechanical properties for the first working group

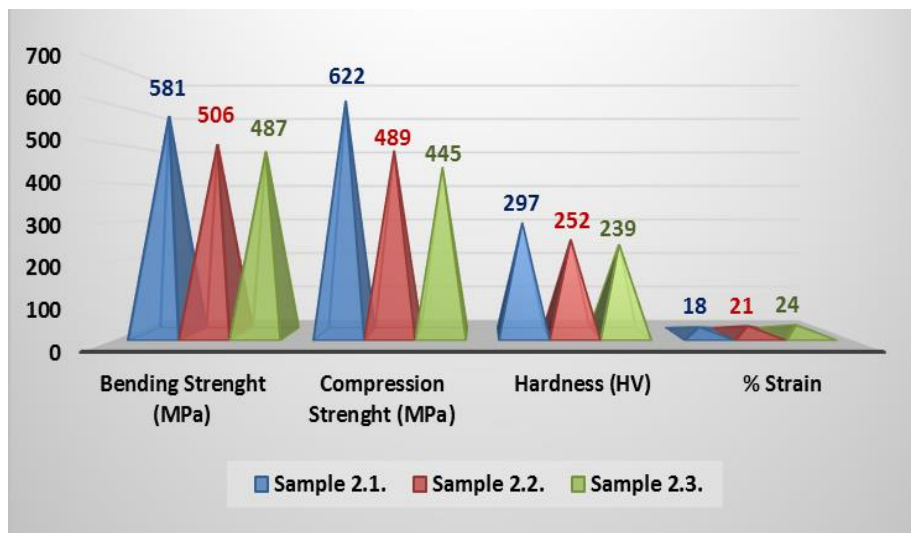

Fig. 13 The comparative mechanical properties for the second working group

\subsection{Microstructural Characterization}

It is well known that the mechanical properties of cast irons at room temperature are very dependent on lots of different parameters. These are solidification microstructure, consisted phases in the matrix, chemical composition and size, shape, and distribution of graphite. There are other factors also affecting the microstructure of gray cast irons such as inoculants and thickness of sections. However, the most important is the cooling rate applied during the solidification of the molten metal $[16,17]$. 

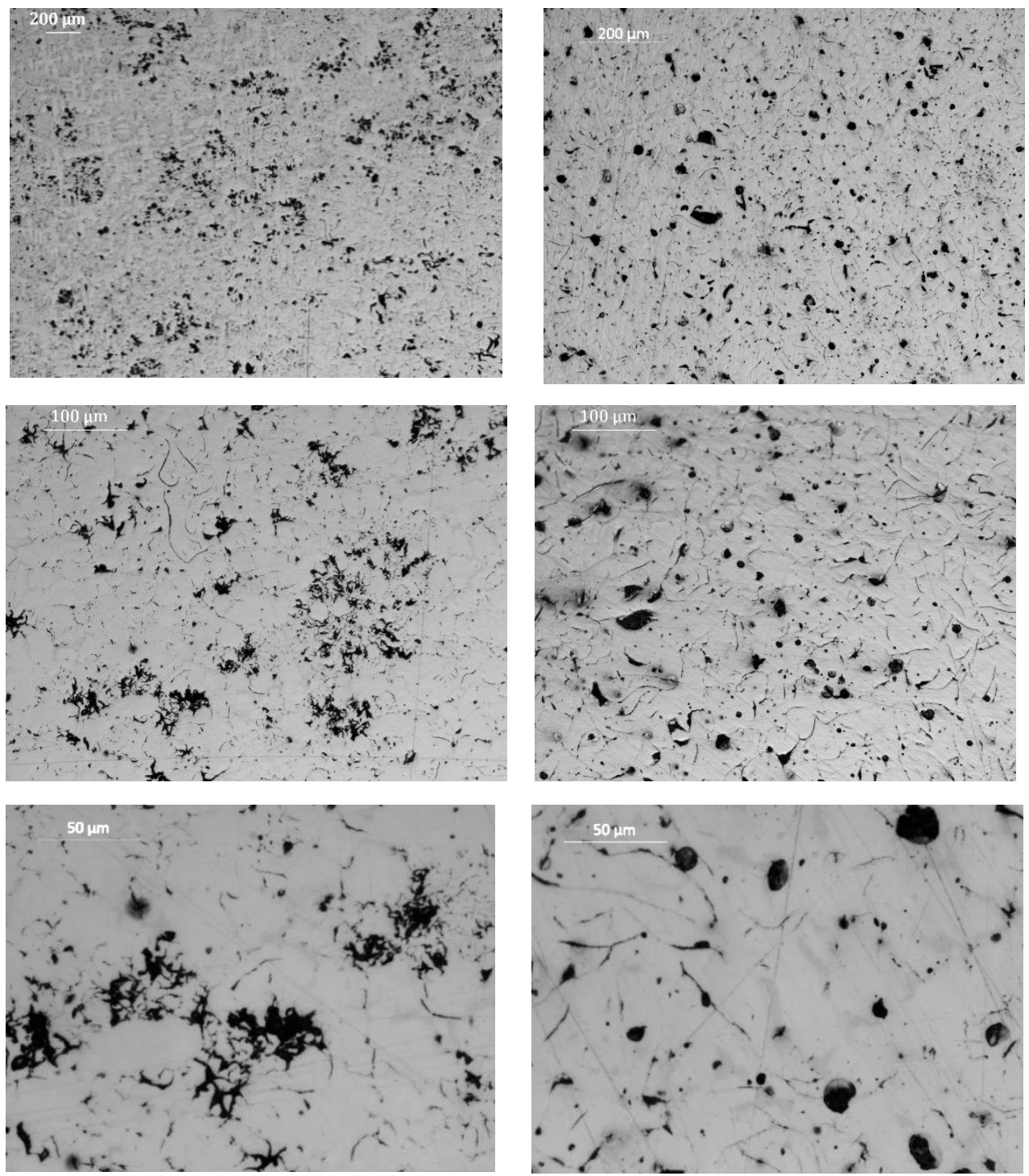

(a) For the sample 1.3. from first working group

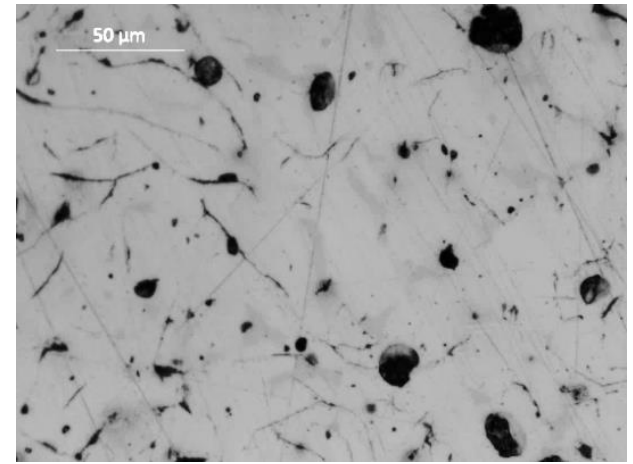

(b) For the sample 2.3. from second working group

Fig. 14 The microstructure of products

In Fig. 14 (a), it is seen the microstructure of provided gray cast iron from group 1.3. For this sample, the silica sand and perlite mixture were used as a mold. The microstructure demonstrates that graphite flakes dispersed heterogeneously on the matrix. It is known that foundry practice can influence nucleation and growth of graphite flakes [18]. The amount of graphite and size, morphology, and distribution of graphite flakes are critical in determining the mechanical properties of gray cast iron. The appearance of graphite flakes is like a rosette group. Since as is known, silicon is an element that facilitates graphitization in the solidification of cast iron, high Si content is thought to be effective in 
the formation of rosette- like graphite without heat treatment. So that the size and type of graphite flakes is important to determine the mechanical properties of castings. The effect of high cooling rates in producing fine microstructures results in the development of high strength cast [17].

Lamellar graphite is classified into five types for foundries and they are designated by capital letters A through E. A lamellar graphite shows random orientation, and it is very suitable for lots of applications. In Fig.14 (b) it is clearly seen A- type [18] graphite structure was formed in produced gray cast iron molded in olivine + perlite mixture. Because of the low thermal conductivities of olivine and perlite, low cooling rate results. These results are very well correlated with the microstructure. In this case, the solidification time is long, the growth rates of the graphite cells are high. This structure gives maximum ductility and toughness [15].

The microstructures of gray iron can be evaluated by cooling rate, composition, nucleation and growth conditions existing during solidification. So, as the undercooling decreases (by a decrease of cooling rate), diffusion rate increases, and the carbon atoms can diffuse more extensively by the time. This results in coarse grains. Rapid cooling produces fine dendrites, while slow cooling results in large and coarse dendrites. Thus, solidification over a temperature range is the primary requirement for dendrite growth [17]. In all samples, it is observed that some porosities and all distributed heterogeneously in the dimension of different sizes. It is not unexpected to see them on the surface because some thermal decomposition of organic components of mold sands can occur during the casting process. This leads to a large emission of gases, and some gas bubbles traps on the surface of the cast. This is a disadvantage for the quality of castings [19].

\section{Conclusions}

The effects of casting mold sand, and binder on the cast iron were investigated. By using silica and olivine as foundry sand at different ratios, bentonite and perlite as binders, the effects of them on the microstructure and the mechanical properties of casting were determined. The results are evaluated based on the thermal conductivity of sands and binders. As a result, the mold sand and binder used in the casting process affects on both the microstructure and the mechanical properties of final castings importantly. Based on this study, the following conclusions are obtained;

- The microstructures of the products show that as the cooling rate goes up, the distribution of graphite particles in the structure changes from nodules to flakes.

- $\quad$ The microstructure of sample 2.3., which olivine and perlite were used as the molding component, show that spherical graphite nodules were obtained without any heat treatment or additive in the lower cooling rate. Especially, this is very important in the manufacturing of products which must have high impact resistance and damping properties. If the casting mold is prepared according to these molding components, the produced part will not need heat treatment again.

- When the cooling rate decreases, the hardness decreases from $310 \mathrm{HV}$ to $239 \mathrm{HV}$ in all of the groups. Also, the bending strength is going from $971.53 \mathrm{MPa}$ to 487.42 $\mathrm{MPa}$, like in the hardness results. On the contrary, the deformation increases from $13 \%$ to $24 \%$ when cooling rates decreases.

In summary, cast iron is used as a raw material for many productions in the industrial applications because of its high carbon content and relatively low mechanical properties. With any probable improvement which can be made in its 
mechanical properties, it will provide pig iron opportunity to be used directly in many more industries. Therefore, a change that will be done in the casting method will provide the desired properties to be obtained at a lower cost.

\section{Acknowledgement}

The authors thank AKIN POMPA in Samsun for their help in casting the samples.

\section{References}

[1] Heine RW, Loper CR, Rosenthal PC. Principles of Metal Castings. 26th reprint, TMH ed. New York, USA, 2003, p. 86.

[2] ELSawy EET, EL-Hebeary MR, El Mahallawi ISE. Effect of manganese, silicon and chromium additions on microstructure and wear characteristics of grey cast iron for sugar industries applications. Wear. 2017; 390: 113 - 124. https://doi.org/10.1016/j.wear.2017.07.007

[3] Gundlach R, Meyer M, Winardi L. Influence of Mn and S on the properties of cast iron part III testing and analysis. International Journal of Metal Casting. 2015; 9: 69 - 82. https://doi.org/10.1007/BF03355617

[4] Sjogren T, Vomacka P, Svensson IL. Comparison of mechanical properties in flake graphite and compacted graphite cast irons for piston rings. International Journal of

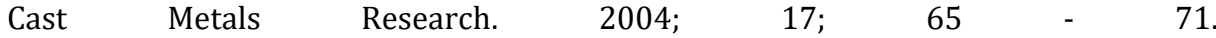
https://doi.org/10.1179/136404604225017474

[5] Nakae H, Shin H. Effect of graphite morphology on tensile properties of flake graphite cast iron. Material Transactions. 2001; 42: 1428 - 1434 https://doi.org/10.2320/matertrans.42.1428

[6] Salazar FR, Herrera-Trejo M, Castro M, Me'ndez JN, Torres JT, Me'ndez M. Effect of Nodule Count and Cooling Rate on As-Cast Matrix of a Cu-Mo Spheroidal Graphite. Journal of Materials Engineering and Performance. 1999; 8: 325 - 329. https://doi.org/10.1361/105994999770346873

[7] Ibitoye SA. Effect of the addition of sodium silicate and bulk density variation on the permeability of potter's clay-bonded moulding sand. Nigerian Society of Engineers Technical Transactions. 2005; 40: 67 - 77.

[8] Gupta AK, Boruah D, Suresh N, Kamal N, Singh AK. Preparation effect of the mould systems on the microstructure and mechanical properties of spheroidised graphite iron. Int. Journal of Engineering Research and Applications. 2016; 6: 68 - 73.

[9] Górny M, Tyrala E. Effect of cooling rate on microstructure and mechanical properties of thin-walled ductile iron castings. Journal of Materials Engineering and Performance. 2013; 22: 300 - 305. https://doi.org/10.1007/s11665-012-0233-0

[10] Adedayo AV. Effects of Addition of Iron (Fe) Filings to Green Moulding Sand on the Microstructure of Grey Cast Iron. Journal of the Brazilian Society of Mechanical Sciences and Engineering. 2010; 32: 171 - 175.

[11] Atanda PO, Olorunniwo OE, Alonge K, Oluwole 00. Comparison of Bentonite and Cassava Starch on the Moulding Properties of Silica Sand. Int. Journal of Materials and Chemistry. 2012; 2: 132 - 136.

[12] Vaou V, Panias D. Thermal insulating foamy geopolymers from perlite. Minerals Engineering. 2010; 23: 1146 - 1151. https://doi.org/10.1016/j.mineng.2010.07.015

[13] Radzikowska JM. Metallography and Microstructures of Cast Iron. The Foundry Research Institute. Kraków, Poland, 2004, $565 \quad$ - 587. https://doi.org/10.31399/asm.hb.v09.a0003765

[14] Petitjean S, Rabinowicz M, Gregoire M, Chevrot S. Differences between archean and proterozoic lithospheres: assessment of the possible major role of thermal 
$\begin{array}{lllll}\text { conductivity. Geochemistry } & \text { Geophysics } & \text { Geosystems. }\end{array}$ https://doi.org/10.1029/2005GC001053

[15] Ichim A, Teodoriu C, Falcone G. Estimation of cement thermal properties through the three-phase model with application to geothermal wells. Energies. 2018; 11: 2839 2850. https://doi.org/10.3390/en11102839

[16] Adedayo AV. Characterization of graphite flakes in grey iron microstructure. Arabian Journal for Science and Engineering. 2012; 37: 1645 - 1652. https://doi.org/10.1007/s13369-012-0265-7

[17] Behnam MMJ, Davami P, Varahram N.Effect of cooling rate on microstructure and mechanical properties of cast iron. Materials Science and Engineering A. 2010; 528: 583 - 588. https://doi.org/10.1016/j.msea.2010.09.087

[18] Collini L, Nicoletta G, Konecna R. Microstructure and mechanical properties of pearlitic gray cast iron. Materials Science and Engineering A. 2008; 488; 529 - 539. https://doi.org/10.1016/j.msea.2007.11.070

[19] Orlenius J, Dioszegi A, Dioszegi Z. Gas absorption in grey cast iron during mould filling. International Journal of Cast Metals Research. 2008; 2: 427 - 434. https://doi.org/10.1179/136404608X373140 